\title{
Case Study on Installation of Aids to Navigation Along the Inland Waterways
}

\author{
Min-Su Jeon* ·Joong Woo Lee ${ }^{\dagger} \cdot K^{-}$-Dam Kim** $\cdot$ Kyu-Kwang Kim*** \\ ****Korea Association of Aids to Navigation, Gasan-dong, Geumcheon-gu, Seoul, Korea \\ +Division of Civil and Environmental Engineering, Korea Maritime Univ. Busan 606-971, Korea \\ ***Department of Civil and Environmental Engineering, Korea Maritime Univ. Busan 606-971, Korea
}

\begin{abstract}
Road and maritime transport which connecting main cities in the world is already fully saturated, and the loss cost caused by recent high oil prices is getting bigger. Transportation by inland waterway is rising as an alternative method of them. Concerning this, the GI Waterway is on construction to connect the Yellow sea and Seoul. Nevertheless, there are no existing aids to navigation around the area and no studies have been carried out for them. As the construction progresses, installation of proper aids to navigation should be considered and profound studies need to be carried out. This study focused on introduction of the cases and the systems of other countries inland waterway aids to navigation and suggested a suitable navigation aids system along the inland waterways in Korea and a way of installation for that system.
\end{abstract}

Key words : inland waterway, GI waterway, system of other countries, suitable navigation aids system

\section{Introduction}

Increasing demand of traffic could cause social cost and it will be worse as the individual traffic volume increases following with the economic development and the raised incomes. The cost of the traffic congestion is being over 15 trillion Korean won as of 2006 and occupies 2 to 3\% in the Gross Domestic Product in R.O.K(Jo and Lee, 2006). Things are trending toward that the cost increases as not less than 1 trillion Korean won every year. Hence, it is said that the inland waterway transportation could help to reduce the cost of the traffic congestion. Concerning this, the GI Waterway is on construction for connection of the Yellow sea and Seoul to improve and enhance the coastal shipping around the country. Nevertheless, there are no existing aids to navigation around the area and no studies have been carried out for them. As the construction progresses, installation of proper aids to navigation should be considered and more profound studies for design are necessary. In the study, it is intended to analyze the foreign inland waterway transport, and to look for the suitable domestic system and the operation method of it in the domestic inland waterways.

\footnotetext{
* First Author : minsuids@hanmail.net 02)2627-8308

† Corresponding author: Joong Woo Lee, jwlee@hhu.ac.kr 051)410-4461

**allyesyou@hanmail.net 02)2627-8308

*** likemark@nate.com 051)410-4981
}

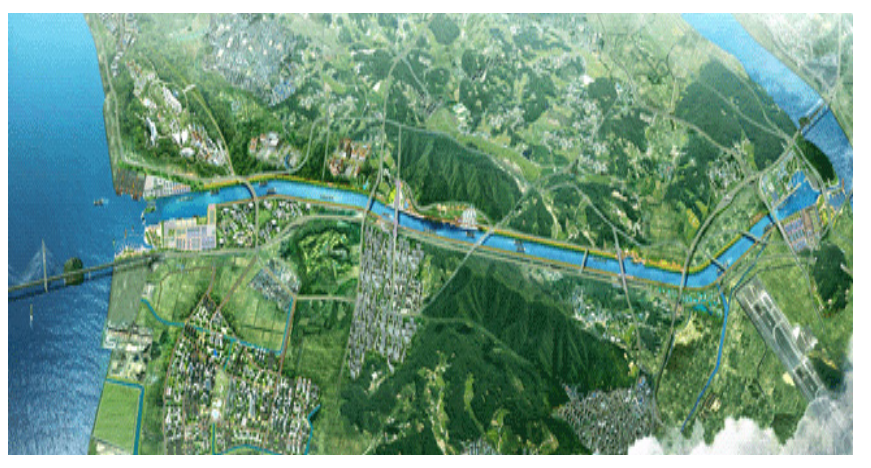

Fig. 1 Bird eye-view of the GI Waterway

\section{Inland waterway aids to navigation related theories}

Typically, navigation has been classified into three categories: ocean navigation, coastal navigation and restricted waters navigation. A far from kinds of navigations, navigating in inland waterway requires extra cautions because of its narrow and long channel. The navigators keep checking the distance from the bank and speed of the ship. For design of inland waterways, it is necessary to consider various circumstances together with different parameters. In the term "Aids to Navigation", it includes the visual aids such as lighthouses, buoys, beacons, leading lines, etc. and the radio aids to navigation such as radar reflectors, radar 
transponders, etc. Furthermore, the satellite radio navigation systems such as GNSS and DGNSS etc. and AIS and VTS are also to be included. Inland waterway requires a complete system of the aids to navigation but this study focused on visual aids as the first step of planning. Many kinds of visual aids were concerned and theories on them were analyzed respectively.

\subsection{Buoys}

Floating aids to navigation serves a similar purpose to a lighthouse on water, many kinds of floating aids could be used for, but buoys can be installed to let the navigators inform the location of hazard or edge of the channel. Particularly, Small and light plastic buoys could be chosen for narrow and shallow channel considering various technical concerns that should be taken into account such as the cost, buoy design, mooring design, swing radius and positioning. At the process of designing a buoy to meet specific requirements, water level, velocity, current of the waterway, it should be considered as its environmental circumstances. Many types of buoys are adopted in many countries with various materials and shapes through the computer simulations. The following equation is to figure out the flow forces by calculating the wind force and current force.

$$
\begin{aligned}
F=F a+F c= & \left(1 / 2 \times \rho_{a} \times C_{d} \times A^{\prime} \times V_{a}^{2}\right) \\
& +\left(1 / 2 \times \rho_{w} \times C_{d} \times A^{\prime} \times V_{c}^{2}\right)
\end{aligned}
$$

Where the variables are

$\rho=\operatorname{density}\left(\rho_{a}\right.$ :wind, $\rho_{c}$ :current $)$

$C_{d}=$ drag force coefficient

$A=$ projected section area

$V=$ velocity of flow $\left(V_{a}\right.$ :wind, $V_{c}$ :current $)$

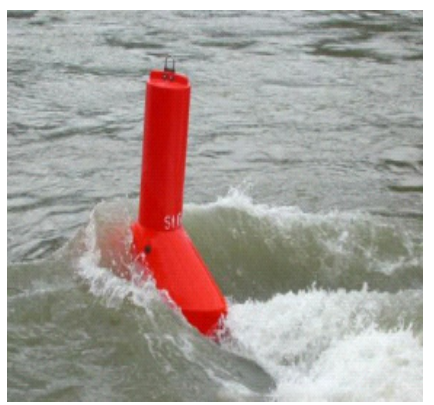

Oval buoy B5 1,0 m/s

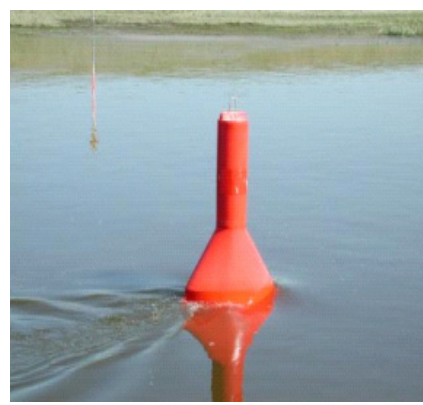

Oval buoy B7 $3,0 \mathrm{~m} / \mathrm{s}$
Fig. 2 Motion of buoys with different velocities

\begin{tabular}{|c|c|c|c|c|}
\hline \multirow{2}{*}{ Name } & Spar buoy & $\begin{array}{c}\text { Oval } \\
\text { buoyB5 }\end{array}$ & $\begin{array}{c}\text { Oval } \\
\text { buoyB7 }\end{array}$ & $\begin{array}{c}\text { Standard } \\
\text { buoy }\end{array}$ \\
\hline & Red & Red & Green & Red \\
\hline Illustration & & & & \\
\hline Weight & $159.1 \mathrm{~kg}$ & $136.7 \mathrm{~kg}$ & $170.7 \mathrm{~kg}$ & $85.5 \mathrm{~kg}$ \\
\hline $\begin{array}{c}\text { Weight } \\
\text { PE-body }\end{array}$ & $56.5 \mathrm{~kg}$ & $36.7 \mathrm{~kg}$ & $51.2 \mathrm{~kg}$ & $61.1 \mathrm{~kg}$ \\
\hline $\begin{array}{l}\text { Weight } \\
\text { reflector }\end{array}$ & $4.1 \mathrm{~kg}$ & $2.3 \mathrm{~kg}$ & $2.3 \mathrm{~kg}$ & $4.2 \mathrm{~kg}$ \\
\hline $\begin{array}{l}\text { Ballast } \\
\text { weight }\end{array}$ & $93.7 \mathrm{~kg}$ & $95.1 \mathrm{~kg}$ & $114.3 \mathrm{~kg}$ & $20.2 \mathrm{~kg}$ \\
\hline $\begin{array}{l}\text { Overall } \\
\text { height }\end{array}$ & $3,255 \mathrm{~mm}$ & $2,140 \mathrm{~mm}$ & $2,310 \mathrm{~mm}$ & $2,047 \mathrm{~mm}$ \\
\hline $\begin{array}{c}\text { Width } \\
\text { (diameter) }\end{array}$ & $\varnothing 400 \mathrm{~mm}$ & $500 \mathrm{~mm}$ & $700 \mathrm{~mm}$ & $\varnothing 1,050 \mathrm{~mm}$ \\
\hline Length & / & $1,180 \mathrm{~mm}$ & $1,570 \mathrm{~mm}$ & 1 \\
\hline Freeboard & $1,200 \mathrm{~mm}$ & $\underset{\mathrm{m}}{1,100-1,300 \mathrm{~m}}$ & $\underset{\mathrm{m}}{1,200-1,400 \mathrm{~m}}$ & $\underset{\mathrm{m}}{1,050-1,160 \mathrm{~m}}$ \\
\hline
\end{tabular}

Table 1 Type of buoys in German Inland Waterway

\subsection{Leading line}

A leading line is an aid to navigating system that comprises two separated structures with marks or lights that, when viewed from the centerline or deepest route along a straight section of channel, are aligned. In a two station leading line, the structures lie along the extension of the centerline for the nominated channel. The rear structure must have a greater elevation than the front structure allowing both marks and/or lights to be viewed simultaneously. A leading line provides a vessel with a heading reference and a visual indication of the size and direction for any cross track error.

Design of the leading line should consider the proper position of the towers for:

1) Better identification of the marks when the ship is at the inner and outer sections of the channel and readily detect cross track position errors from the centerline of the channel;

2) Less errors with sufficient sensitivity that the channel can be utilized without abrupt changes to the vessels heading and speed;

The characters of rhythmic leading lights should be selected so that the front and rear lights, in their free running states, can generally be observed together. If lights are to be used both day and night, the light intensities should be adapted for each situation to avoid glare at night. The location, intensity of the light and level difference can be 
calculated as following equations.

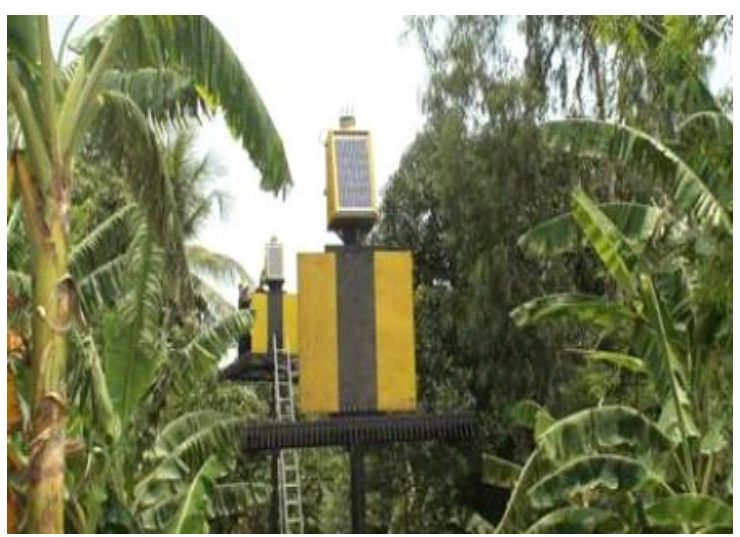

Fig. 3 Leading lines for inland waterway in Cambodia

The distance between the front and rear lights "R" can be calculated by following equation.

$$
R=(M+C) /\left[100 W /\left(3.4 \times 10^{-3}\right)(M+C)-1\right]
$$

Where variables:

$\mathrm{M}=$ Distance between near and front light

$\mathrm{C}=$ Channel length

Where the variable $\mathrm{M}$ is the distance between near and front light and $\mathrm{C}$ is the channel length. The intensity in candelas "I" can be calculated by following equation.

$$
I=D^{2}-E / 0.05^{-(D / 18520)}
$$

Where variables:

$\mathrm{D}=$ Distance from the light to the far end of the channel in meters

$\mathrm{E}=$ Threshold of illuminance in lux

Where the variable $\mathrm{D}$ is the distance from the light to the far end of the channel in meters and $\mathrm{E}$ is a threshold illumination in flux. The following equation determines the vertical separation in milliradians required to prevent the lights from blurring together(IALA AISM, 2005):

$$
\begin{gathered}
\gamma=\frac{H_{2}-b-c-6.75 \times 10^{-8}(x+R)^{2}}{x+R} \\
-\frac{H_{1}-b-c-6.75 \times 10^{-8} x^{2}}{x}
\end{gathered}
$$

Where the variables are:

$H_{2}=$ rear tower height at mean low water in meters

$H_{1}=$ front tower height at mean low water in meters

$b=$ height of eye in meters $c=$ mean range of tides in meters

$x=$ distance from front tower to observer in meters

$R=$ distance between towers in meters

\subsection{Bridge mark and information board}

In some cases, bridge marks are desirable and necessary to indicate vessels the most appropriate point to pass under a bridge. The passage point could be determined considering all relevant factors, such as:

1) Maximum available headroom

2) Water depth under the bridge, particularly where it is not uniform

3) Protection of the bridge piers and other obstructions

4) The necessity of one way or two way traffic

If it is possible to navigate in the full passage span, the marks should be located at the bridge piers. If it is possible only in part of the span, the marks should be located at or under the span, indicating the limits of the navigable channel. Many kinds of information boards have been used in many countries and they have adopted their own types. European use "Guideline for waterway signs and marking"(UN, 2006) and South East Asian countries use their types of marks to indicate hazards or dangerous spots and inform the navigators with required information along the channel. The shape and size of the information board should be decided from the result of studies on shape science, human and navigation engineering.

Table 1 Recognition abilities of shapes in an order

\begin{tabular}{|c|c|c|c|c|c|c|c|}
\hline Order & 1 & 2 & 3 & 4 & 5 & 6 & 7 \\
\hline \multirow{2}{*}{ Shape } & Triangle & Diamond & Square & Rectangular & Pentagon & Circle & Hexagon \\
\cline { 2 - 8 } & & & & & & & \\
\hline
\end{tabular}

Source : $\operatorname{MOMAF}(2007)$

The boards should be clear, concise, understandable and appropriate signage is the key to ensure safe navigation. For better visional recognition of the boards a proper experimental experience and theoretical calculation are required for many different environmental conditions: amount of clouds, particles in the air, the temperature variation, intensity and direction of the light beam, etc. could make wide spectrum of recognition. The shape of the board also could make difference, because of its recognition abilities. 


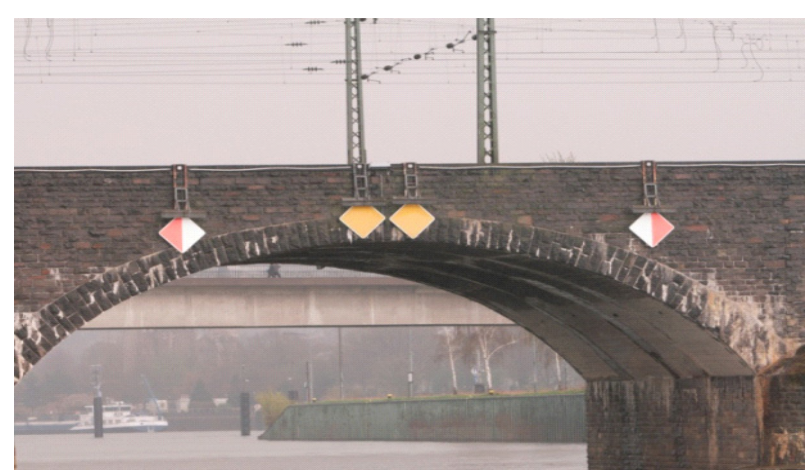

Fig. 4 Bridge marks on a German bridge
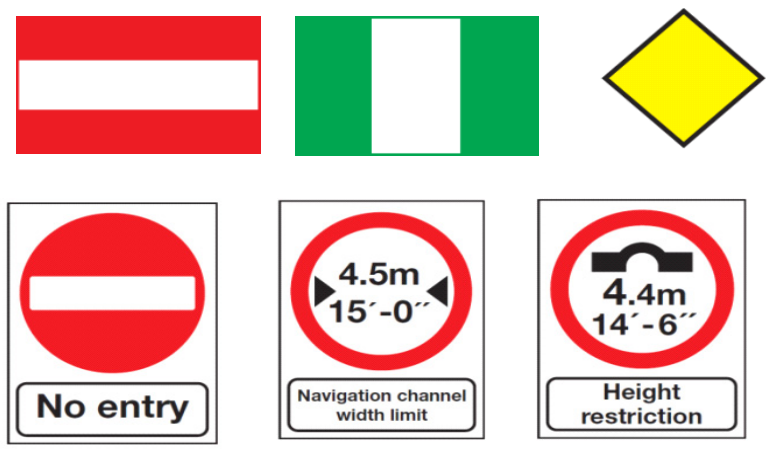

Fig. 5 Information board for European Countries Source : United Nations (2006)

The recognizable distance by the area can be calculated by following equation:

$$
D_{s}=\frac{\sqrt{A}}{\tan \theta}
$$

Where variables:

$$
\begin{aligned}
& \mathrm{A}=\text { Area } \\
& \theta=\text { Visual angle }
\end{aligned}
$$

\subsection{Other aids to navigation facilities}

A light pole is a simple structure which notifies vessels of the location in which buoy lanterns and radar reflectors are installed. They can be installed in narrow areas of the waterway and at the entrance to port facilities which cause vessels difficulty when navigating. Crossing marks, which indicate sharp veering locations, so as to allow vessels to recognize veering points in the inland waterway, need to be installed. Distance marks, on which a series of numbers or characters are stated, so as to indicate distances in order for vessels navigating the inland waterway to recognize their positions even without auxiliary navigation devices also need to be installed.

\section{Inland waterway aids to navigation systems}

\subsection{Europe}

The inland waterways offer a 35,000km congestion-free

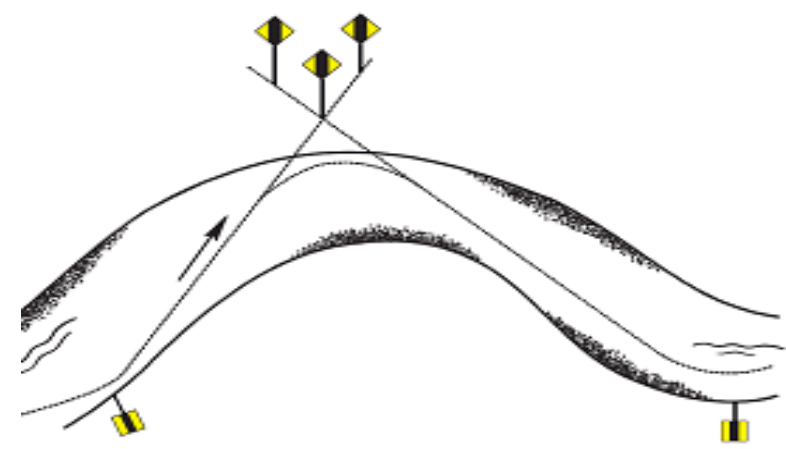

Fig. 6 Cross $^{-}$over mark

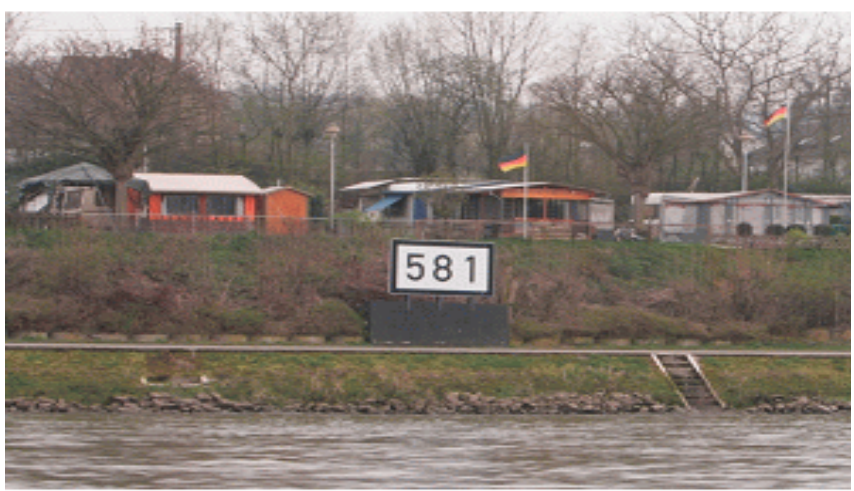

Fig. 7 Distance mark

network connecting cities across Europe and half this network is accessible to 1,000t vessels. The inland waterways form a particularly dense network in North-West Europe where waterway transport is essential to the competitiveness of some major sea ports, providing a seamless network for transportation inland. More than 50\% of sea tonnage from Antwerp and Rotterdam is carried inland by barge.

The Inland waterway system in EU(CEVNI, 1985; EU,2005) is based on the Guideline for Waterway Signs and Markings which was developed by the Economic Commission for Europe. England mainly adopted the rules, but different types of Information boards are being used. Primarily, countries from Europe and North America use inland waterway traffic facilities. There are differences between countries in that, in general, the entire International Convention for the Safety of Life at Sea (SOLAS) treaty and the International Maritime Organization (IMO) guide have not been uniformly applied. 


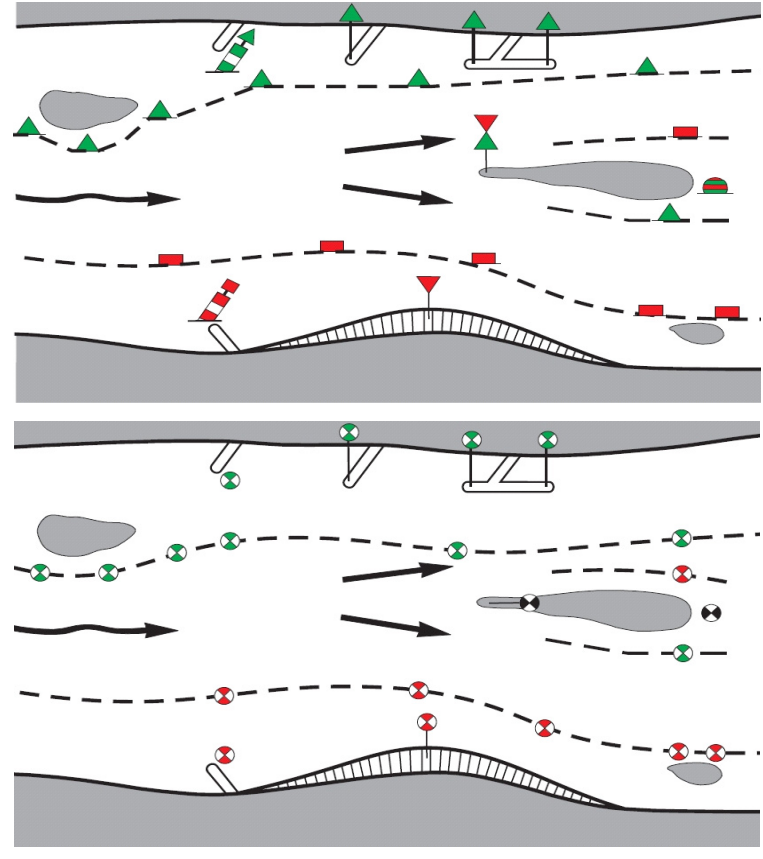

Fig. 8 Example of use of the marks in Europe Source : United Nations (2007)

Table 2 RIS System Services

\begin{tabular}{|c|c|}
\hline Classification & Types of Services \\
\hline $\begin{array}{l}\text { Navigation } \\
\text { information } \\
\text { service }\end{array}$ & $\begin{array}{l}\text { Visual aid (shape aids, light wave aids) } \\
\text { Wireless communication service } \\
\text { Internet service } \\
\text { Electronic Navigation Chart (ENC) } \\
\text { service }\end{array}$ \\
\hline $\begin{array}{l}\text { Traffic } \\
\text { management }\end{array}$ & $\begin{array}{l}\text { Regional traffic management (VTS) } \\
\text { Navigation support } \\
\text { Lock gate/bridge management }\end{array}$ \\
\hline $\begin{array}{l}\text { Logistics } \\
\text { management } \\
\text { information }\end{array}$ & $\begin{array}{l}\text { Navigation plan } \\
\text { Transport management } \\
\text { Port/terminal management } \\
\text { Cargo/fleet management }\end{array}$ \\
\hline $\begin{array}{c}\text { Statistics } \\
\text { information }\end{array}$ & $\begin{array}{l}\text { Vessel navigation traffic information } \\
\text { Strategic significant traffic information }\end{array}$ \\
\hline $\begin{array}{c}\text { Traffic } \\
\text { information }\end{array}$ & Transport-related matters \\
\hline $\begin{array}{l}\text { Accident } \\
\text { protection } \\
\text { support } \\
\end{array}$ & - \\
\hline $\begin{array}{c}\text { Information for } \\
\text { law enforcement }\end{array}$ & - \\
\hline $\begin{array}{l}\text { Waterway/port } \\
\text { charge }\end{array}$ & - \\
\hline
\end{tabular}

In Europe, the River Information Service (RIS) is provided to improve safety and navigation efficiency in inland waterways, and also to protect the environment. It is preferable that typical inland waterways provide aids to navigation together with the construction of the River
Information Service (RIS) system in order to accomplish traffic management, logistics management, statistics management, accident protection, etc. in addition to the service of providing navigation information.

First, the RIS provides navigating vessels with a basic navigation information service that provides visual aid through shape aids and light wave aids, a wireless communication service, an Internet service, and the ENC service. This provides fundamentally required information on navigation routes of inland waterways to navigating vessels. Also, the RIS provides a logistics management information service, enabling navigation-plan management, transport management, port/terminal management, and cargo/fleet management by using the AIS (Automatic Identification System). In addition, the RIS provides information on statistics and traffic, as well as accident protection, information for law enforcement, and the service of collecting waterway/port charges.

The RIS is based on the sharing of electronic information between vessels and the land center, requiring the installation of light wave aid facilities, such as AIS, VHF base stations, an Internet service, and a light wave channel direction board.

\subsection{United Kingdom}

The UK is one of the European countries, but different for the information boards as they are separated from other states and developed an industry standard for UK inland waterways. 5 kinds of standard boards; Restriction(black on white within a red circle), Prohibition(black on white within a red crossed circle), Hazard Warnings(black on yellow within a black edged yellow triangle), Mandatory(white symbols within a blue circle) and Information board(black lettering/symbols on a white background) are used for the purposes.

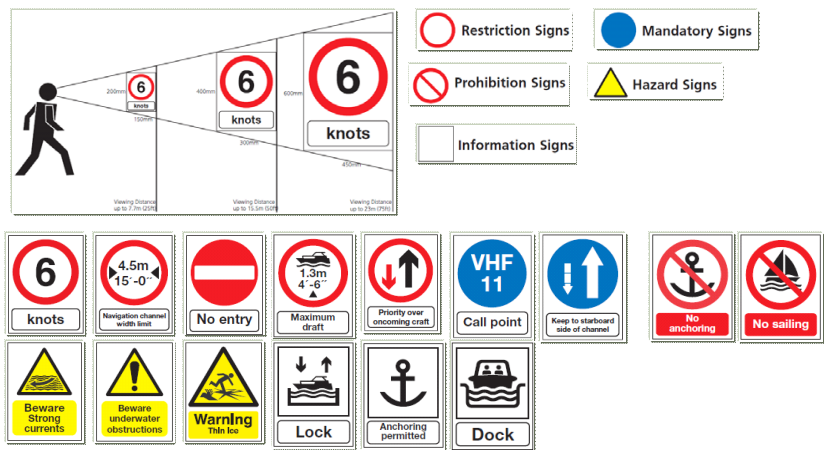

Fig. 9 Examples of English inland waterway information Board

Source : Association of inland navigation authorities (2006) 


\subsection{South East Asia(Cambodia)}

The inland waterway of South East Asia was concerned, particularly Cambodia where among the riparian countries of the Mekong uses the river importantly for their domestic purpose and many kinds of aids to navigation along the river. Although, the existing aids to navigation installed on the River are extremely insufficient to meet the demand from increasing international and domestic traffic on the River.

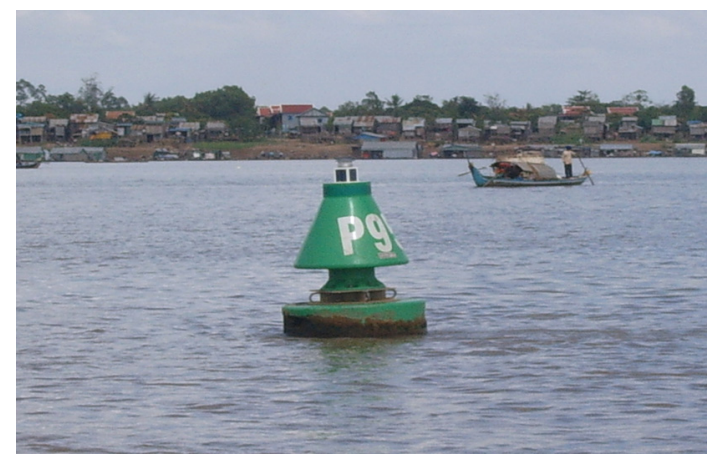

Fig. 10 Installed small plastic buoy in Cambodia

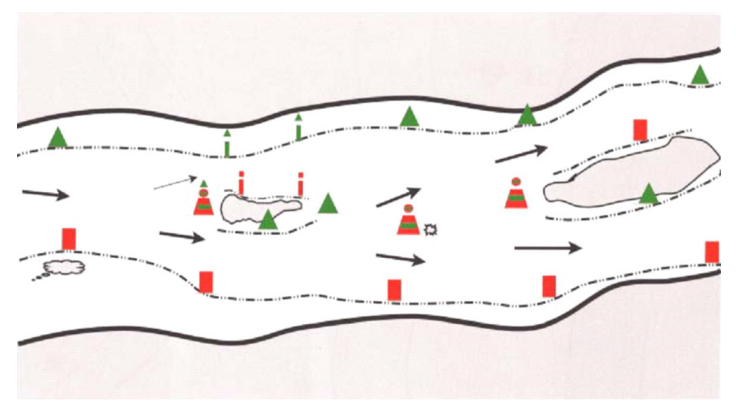

Fig. 11 Example of use of the lateral and bifurcation marks in the mekong river

Source : ESCAP \& MRC (2002)

In order to promote safe navigation on the Greater Mekong River, the Economic and Social Commission for Asia and the Pacific (ESCAP) and the Mekong River Commission (MRC) jointly initiated a project on harmonization of aids to navigation systems in 1996 to assist the riparian countries in formulating and implementing a harmonized aids to navigation system to ensure safe navigation for the sake of passengers' lives, people's properties and the environment. (ESCAP \& MRC, 2009; MLTM \& KAAN, 2009)

The Mekong river originates in Tibet of China, and is $4,020 \mathrm{~km}$ in total length, extending through Myanmar, Laos, Thailand, Cambodia, and Vietnam through to the South-China sea and, with a total area of $800,000 \mathrm{~km}^{2}$, it is the greatest river in South-east Asia. The Mekong river is influenced with a seasonal wind so as to have its lowest water level in the dry season from March to May, and the water level increases in the rainy season with the blowing of the southwesterly seasonal wind. Notably, the size of the Tonle Sap lake grows by about 3 times in the rainy season in comparison with that of the dry season.

The total inland waterway aids to navigation installed in Cambodia at present consists of 56 light buoys and 10 leading lights installed in the section between Phnom Penh and the Vietnamese border. These inland waterway aids to navigation were installed in April 27, 2007, after on-site research from 2006 through 2007.

\section{Conclusions}

Aid to Navigation is a device or system external to vessels that is designed and operated to enhance the safe and efficient navigation of vessels and vessel traffic. Many studies for aids to navigation have been carried out, but they were mostly focused on marine environment. These days, inland waterway is rising as an alternative method of road and maritime transportation. Besides, the different circumstances and parameters should be considered, too. The final purpose of this study is to develop aids to navigation system for the Seoul-Incheon inland waterway as well as the proper equipments for the waterway. Many cases and systems need to be considered and analyzed for the process and it must come with establishment of competent regulations for inland waterways.

As a preliminary study, inland waterway aids to navigation theories of buoys, leading line, bridge mark, information board and other facilities were analyzed and cases of Europe, the UK and South East Asia was considered to develop the system for the waterway. According to the case studies of each country, a customized resolution for waterways must be find out as the environment varies even in a waterway. For the next study, the circumstances of the GI Waterway will be applied for the theoretical study and a set of aids to navigation will be derived as well as the opinions of the navigator.

\section{References}

[1] Association of inland navigation authorities (2006), Navigation signs and symbols(An industry standard for UK inland waterways), p6.

[2] ESCAP \& MRC (Economic and Social Commission for Asia and the Pacific \& Mekong River Commission, 2002), Recommended Aids to Navigation Systems on the 
Greater Mekong River, p13.

[3] IALA AISM (2005), IALA Recommendation E-112 on leading lights, edition 1.1, p.13.

[4] Jo, H. S., Lee, D. M. (2006), "2006 Traffic Congestion Costs: Estimation and Trend Analysis", Korea Transport Institute.

[5] MLTM \& KAAN (Ministry of Land, Transport and Maritime Affairs \& Korea Association of Aids to Navigation, 2009), Preliminary Feasibility Study on Aids to Navigation Installation Project in Cambodian Inland Waterways, p29.

[6] MOMAF (Ministry of Maritime Affairs and Fisheries, 2007), Study for proper arrangement of buoys for approach routes of the trade ports, p3-12.

[7] United Nations (2007), CEVNI(European Inland Waterway Navigation Cod), Third revised edition, p142-161.

[8] United Nations (2006), Guidelines for Waterway Signs and Marking Resolution No.59, p20.

Received 25 November 2009

Revised 31 December 2009

Accepted 31 December 2009 